\title{
Absence of MYCN Gene Amplification
}

National Cancer Institute

\section{Source}

National Cancer Institute. Absence of MYCN Gene Amplification. NCI Thesaurus. Code C116945.

A molecular finding indicating the absence of multiple copies of the MYCN gene in a tissue sample. 